\title{
Boas Práticas de Gestão e Capacidade Absortiva: Impactos na Produtividade das Firmas
}

\author{
Good Management Practices and Absorptive Capacity: Impacts on Firms' \\ Productivity
}

\section{RESUMO}

Contexto: poucos são os estudos que visam a calcular a produtividade em nível microeconômico e uma das variáveis que contribuem para isso é a capacidade das firmas de absorver o conhecimento externo - capacidade absortiva. Contudo, outra variável também vem ganhando poder de explicação nessa direção - a das boas práticas de gestão. Ocorre que não se encontra facilmente estudos que tratem essas duas variáveis em conjunto e que as relacione com a produtividade. Objetivo: o objetivo desta pesquisa é entender como se dá a interação entre boas práticas de gestão e a capacidade absortiva das firmas e seu impacto sobre a produtividade. Método: foi utilizado o método multicasos, tendo este sido aplicado em indústrias transnacionais e nacionais. Resultados: os resultados apontam que a existência de boas práticas de gestão atua como uma influenciadora da capacidade absortiva, e que tal relação gera um impacto positivo sobre a produtividade das firmas. Ademais, foi revelado que os processos de gestão nas empresas transnacionais contribuem de forma mais efetiva quanto à capacidade absortiva e produtividade do que nas empresas nacionais. Conclusões: como contribuição, é apresentado um modelo de análise que demonstra as relações entre as variáveis estudadas, podendo-se evidenciar a importância das boas práticas de gestão como determinante ao desenvolvimento da capacidade absortiva e à melhoria das condições de produtividade das firmas.

Palavras-chave: boas práticas de gestão; capacidade absortiva; produtividade.
${ }^{1}$ Centro Universitário FEl, São Bernardo do Campo, SP, Brasil.

${ }^{2}$ Universidade de São Paulo, Faculdade de Economia, Administração e Contabilidade, São Paulo, SP, Brasil.

Como citar: Jacomossi, R. R., \& Feldmann, P. R. (2020). Good management practices and absorptive capacity: Impacts on firms' productivity. Revista de Administração Contemporânea, 24(5), 432-447. https://doi.org/10.1590/1982-7849rac2020190140

\section{ABSTRACT}

Context: there are few studies that aim to calculate productivity at the microeconomic level and one of the variables that contributes to this is the ability of firms to absorb external knowledge absorptive capacity. However, another variable is also gaining explanatory power in this direction - that of good management practices. It turns out that studies that deal with these two variables together and that relate them to productivity are not easily found. Objective: the objective of this research is to understand how the interaction between good management practices and the absorptive capacity of firms and the impact on productivity takes place. Method: the multi-case method was used, having been applied in transnational and national industries. Results: the results show that the existence of good management practices acts as an influencer of absorptive capacity, and that this relationship has a positive impact on the productivity of firms. Furthermore, it was revealed that management processes in transnational companies contribute more effectively to absorptive capacity and productivity than in national companies. Conclusions: as a contribution, an analysis model is presented that demonstrates the relationships between the variables studied, showing the importance of good management practices as a determinant for the development of absorptive capacity and the improvement of firms' productivity conditions.

Keywords: good management practices; absorptive capacity; productivity.

ditor-chefe: Wesley Mendes-Da-Silva (Fundação Getulio Vargas, EAESP, Brasil) Pareceristas: Renata B. B. de Vasconcelos (Universidade Federal de Pernambuco, Brasil) [ Paulo H. Ferreira-Alves (Universidade de Brasília, Instituto de Psicologia, Brasil) (C)

Recebido em: 12/04/2019 Úlłima versão recebida em: 19/04/2020 Aceite em: 22/04/2020

\# de revisores convidados até a decisão:

\begin{tabular}{|c|c|c|c|c|c|c|c|c|c|}
\hline & 1 & 2 & 3 & 4 & 5 & 6 & 7 & 8 & 9 \\
\hline $1^{a}$ rodada & (x) & 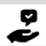 & $\stackrel{\infty}{\infty}$ & (x) & (x) & (x) & & & \\
\hline $2^{a}$ rodada & 2 & & & & & & & & \\
\hline $3^{a}$ rodada & 8 & & & & & & & & \\
\hline
\end{tabular}




\section{INTRODUÇÃO}

A relação entre inovação e seu potencial para promover o aumento da competitividade já é consagrada na literatura (Freeman, 1987; Nelson \& Winter, 1982; Pavitt, 1984; Schumpeter, 1982). Por outro lado, a fim de que um país ou uma empresa se torne mais eficiente em seus mercados de atuação, é necessário que haja a melhoria dos seus índices de produtividade, sendo este, portanto, um condicionante para o aumento da competitividade (Carayannis \& Grigoroudius, 2014; Gordon, 2016; Ledereman, Messina, Pienknagura, \& Rigolini, 2014).

Há, portanto, uma relação intrínseca entre a atividade inovativa e os ganhos de produtividade. Uma evidência é o trabalho pioneiro de Griliches (1979) que relacionou os efeitos de gastos de P\&D sobre a produtividade, sinalizando que esta última é decorrente de inovações e de sua incorporação no processo produtivo. Outros trabalhos sobre a temática (Gordon, 2016; Mairesse \& Robin, 2009; Medda \& Piga, 2014; Parisi, Schiantarelli, \& Sembenelli, 2006; Wakelin, 2001) também corroboram o efeito positivo da atividade inovativa sobre o nível de produtividade das firmas.

Ocorre que a atividade de inovação nasce nas firmas por meio da maneira como estas absorvem o conhecimento no ambiente externo e o internalizam em seu contexto interno, provocando mudanças nas rotinas e cultura, contribuindo, assim, para a atividade de inovar. Este fenômeno é chamado de capacidade absortiva (absorptive capacity).

Segundo Cohen e Levinthal (1990), Nelson e Winter (1982) e Zahra e George (2002), este elemento de análise envolve o processo utilizado pela firma a fim de buscar novos conhecimentos e tecnologias no ambiente externo e sobre como estes são introduzidos e/ou readaptados nas rotinas organizacionais. Dessa forma, a inovação dentro de uma empresa pode ser vista como o resultado decorrente de um processo de aprendizagem organizacional (Jacomossi \& Demajorovic, 2017; Nelson \& Winter, 1982), por meio do qual diversas rotinas são ativadas e/ou readaptadas podendo, como resultado, contribuir para a inovação de produtos e processos. Portanto, a capacidade absortiva é um conjunto de rotinas derivadas da capacidade de a empresa aprender.

Contudo, ainda que se associe o aumento de produtividade à capacidade absortiva ou outras variáveis, outra explicação que está emergindo na literatura se refere à existência de melhores práticas de gestão nas organizações, com diversos estudos apontando para a importância deste elemento para se aumentar a eficácia organizacional (Agarwal, Brown, Green, Randhawa, \& Tan, 2014; Bloom \& Van Reenen, 2010; Feldmann, 2009; Feldmann,
Jacomossi, Barrichello, \& Morano, 2019; Kerzner, 2018; Mundlack, 1961). Assim, a empresa que segue práticas de gestão orientadas por resultados está potencializando sua própria competitividade. $\mathrm{Na}$ pesquisa realizada por Bloom e Van Reenen (2010), há uma diferença significativa de melhores práticas de gestão entre os países, figurando o Brasil nas últimas posições.

Diante do exposto, percebe-se que tanto a dimensão relativa à capacidade absortiva da organização quanto a relativa às boas práticas de gestão influenciam o aumento da produtividade. Por outro lado, não se encontram facilmente na literatura trabalhos que relacionam esses dois construtos de modo combinado, verificando os impactos destes sobre a produtividade. Assim sendo, fazse necessário também investigar a forma pela qual essas interações ocorrem. Isto posto, surge uma lacuna de pesquisa que necessita ser preenchido, justificando-se, dessa forma, o desenvolvimento deste estudo. Diante do exposto, suscita-se, portanto, o seguinte problema de pesquisa: como ocorre, na organização, a interação entre as dimensões boas práticas de gestão e capacidade absortiva e quais os impactos da combinação destes elementos sobre a produtividade? Adicionalmente, apresenta-se um segundo problema: há diferença entre as práticas de gestão e de capacidade absortiva adotadas por empresas brasileiras e transnacionais de modo a interferir no resultado de produtividade?

As questões de pesquisa direcionam aos objetivos deste trabalho, que residem em analisar e entender de que modo as dimensões capacidade absortiva e boas práticas de gestão interagem, e a partir daí compará-las entre empresas nacionais e transnacionais, verificando os impactos em termos de produtividade dos seus negócios.

Já a contribuição desta pesquisa reside em preencher uma lacuna na literatura que inicie e/ou amplie o debate acerca da importância da combinação dos construtos boas práticas de gestão e capacidade absortiva sobre o nível de produtividade das firmas.

\section{REVISÃO DE LITERATURA}

Esta seção abordará os temas centrais que sustentam esta pesquisa - capacidade absortiva $e$ boas práticas de gestão.

\section{Capacidade absortiva}

Este elemento de análise está associado ao processo de rotinas que envolvem a busca de novos conhecimentos e tecnologias no ambiente externo para a assimilação e adequação das rotinas organizacionais, além do processo inerente para 
conservá-los na empresa. Sendo assim, a capacidade de inovar de uma empresa é dependente deste elemento (Cohen \& Levinthal, 1990; Nelson \& Winter, 1982; Zahra \& George, 2002).

Segundo Cohen e Levinthal (1990) e Zahra e George (2002), a capacidade absortiva é composta por duas dimensões, as quais são subdivididas em outras quatro, sendo elas: Capacidade Absortiva Potencial (Aquisição e Assimilação) e Capacidade Absortiva Realizada (Transformação e Aplicações). A fim de facilitar a compreensão, apresenta-se a tabela abaixo.

Tabela 1. Capacidades absortivas.

\begin{tabular}{|c|c|c|}
\hline \multirow{2}{*}{$\begin{array}{l}\text { Capacidade Absortiva } \\
\text { Potencial }\end{array}$} & Aquisição & $\begin{array}{l}\text { É a habilidade da empresa de localizar, identificar, valorizar e adquirir o } \\
\text { conhecimento externo que é crítico para seu negócio. }\end{array}$ \\
\hline & Assimilação & $\begin{array}{l}\text { São os processos e rotinas que permitem que a nova informação ou } \\
\text { conhecimento adquirido seja analisado, processado, interpretado, } \\
\text { entendido, internalizado e classificado. }\end{array}$ \\
\hline \multirow{2}{*}{$\begin{array}{l}\text { Capacidade Absortiva } \\
\text { Realizada }\end{array}$} & Transformação & $\begin{array}{l}\text { Refere-se ao refinamento do conhecimento externamente adquirido para } \\
\text { adequá-lo aos conhecimentos acumulados da organização, proporcionando } \\
\text { a atribuição de novas rotinas e sua combinação às rotinas internas. }\end{array}$ \\
\hline & Aplicação & $\begin{array}{l}\text { Implantação de rotinas e processos que permitem que o conhecimento } \\
\text { transformado seja agregado às rotinas e operações do negócio. O resultado } \\
\text { de tais rotinas promove como resultado novos processos, produtos, } \\
\text { conhecimento, gerando uma posição mais sustentável à organização. }\end{array}$ \\
\hline
\end{tabular}

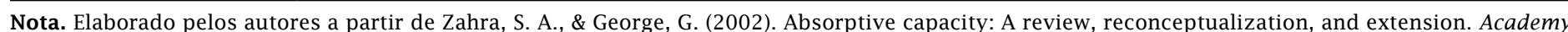
of Management Review, 27(2), 185-203. https://doi.org/10.5465/amr.2002.6587995

A capacidade absortiva captura tanto o conhecimento interno quanto o externo da organização e transforma-o por meio do desenvolvimento e reconfiguração de rotinas, que potencialmente melhoram a capacidade de inovação da firma.

Para Zahra e George (2002), antes de a firma iniciar o processo de capacidade absortiva potencial - aquisição e assimilação, são gerados estímulos de ativação, sendo estes eventos os que ocorrem quando a empresa passa por algum tipo de crise interna ou externa e que demanda mudança estratégica. Assim, a empresa emerge em experiências que visam a buscar conhecimento, tais como: aquisições, compras, relacionamentos interorganizacionais, licenças e acordos comerciais, consórcios de P\&D, alianças e joint ventures. Essas experiências se dão, portanto, por meio de aprendizagem e são cristalizadas na memória da organização (Walsh \& Ungson, 1991), definindo seu modo de operar.

Já Choi (2014) identificou que tanto a formação de memórias quanto a capacidade absortiva influenciam direta e positivamente a qualidade dos relacionamentos na organização. Nessa direção, Kim (2016) inferiu que em empresas que recebem investimento estrangeiro, e em havendo uma boa capacidade absortiva desenvolvida, os resultados são mais promissores.

Além disso, Phoocharoon (2015) e Wang, Zhao e Zhou (2018) comentam que é indispensável ao desenvolvimento da capacidade absortiva o reforço de elementos tais como: a existência de uma liderança transformadora, a orientação dos empregados para a aprendizagem e incentivos que os estimulem a isso.

Ritala e Hurmelinna-Laukkanen (2013) constataramquea capacidadeabsortivaéresponsável pela adoção de inovações incrementais ou radicais por parte da empresa, embora as primeiras ocorram em maior número. Adicionalmente, Kostopoulos, Papalexandris, Papachroni e Ioannou (2011), Tavani, Sharifi e Ismail (2014), Brettel, Greve e Flatten (2011) e Cardozo, Kronmeyer Filho e Vaccaro (2019) relacionaram a capacidade absortiva com a geração de inovações, com a melhoria no desempenho financeiro e com o desempenho da organização.

Uma vez que a capacidade absortiva é adquirida e assimilada pela organização, não é garantido que se avance para as fases de transformação e aplicação (capacidade absortiva realizada). Nesse sentido, Cuervo-Cazurra (2017) identificou como barreira à implementação de estratégias de capacidade absortiva a existência de mecanismos fracos de integração social. Para superar tais barreiras, Armstrong e Lengnick-Hall (2013), Vega-Jurado, Gutiérrez-Gracia e Fernándezde-Lucio (2008) e Zahra e George (2002) postulam, por exemplo, que esses mecanismos podem ser ativados por estruturas organizacionais que 
estimulem a integração entre os funcionários, a criatividade e a resolução de problemas em equipe.

Esses empregados se tornam mais conscientes acerca de sua importância e facilitam o livre fluxo de informações, e segundo Morano, Barrichello e Jacomossi (2016) e Morano, Moraes e Jacomossi (2018), tais mecanismos têm a capacidade de gerar uma coesão que se manifesta por meio de uma identidade social.

Já Guimarães, Thielman, Guimarães e Cornick (2016) reforçam a importância da capacidade absortiva como elemento central e moderador, sendo a inovação o resultado de um processo possibilitado pela existência de estratégias e de uma política de gestão clara, sendo esta última de fato importante para que a empresa adote uma direção clara nas suas estratégias de inovação.

Desse modo, observa-se que a capacidade absortiva se associa também com a capacidade de as firmas gerirem com inteligência seus negócios, o que denota a importância da qualidade de gestão para que se atinja tal intento, sendo essa temática objeto da próxima seção.

\section{Boas práticas de gestão}

Mundlack (1961), Bloom e Van Reenen (2010) e Agarwal, Brown, Green, Randhawa e Tan (2014) comentam que, além de as diferenças de produtividade serem motivadas pelas inovações tecnológicas, podem também ser reflexo da existência de boas práticas de gestão nas organizações.

A própria história econômica justifica essa relação. Landes (1969) e Chandler e Hikino (1994) comentam que a derrocada de firmas inglesas e a pujança das americanas e alemãs no início do século XX ocorreu em função das práticas de gestão adotadas pelas empresas daqueles territórios. Nessa direção, Kerzner (2018) desenvolveu estudos de casos com diversas empresas apontando para a qualidade de suas gestões como um indicador de sobrevivência e sucesso ao longo dos anos.

Já Feldmann, Jacomossi, Barrichello e Morano (2019) realizaram estudo em que verificaram que a competitividade das nações não se explica apenas pela capacidade de inovação, mas que seria necessário o papel mediador de boas práticas de gestão como um indutor ao crescimento dessas variáveis.

Apesar de ser importante o aspecto da qualidade de gestão e da discussão nas melhores business schools ao redor do mundo, nunca houve consenso sobre como medir tal variável. Essa dificuldade se dá pela própria abrangência do campo, que segundo Venkatraman e Ramanujam (1987) pode ser, por exemplo, um comparativo da empresa e seus concorrentes em aspectos como: sucesso comercial do negócio; índices contábeis relacionados à rentabilidade, às margens de vendas e à produtividade dos negócios, ou outros.

No entanto, há poucos instrumentos validados para essa mensuração e, para suprimir essa lacuna na literatura, Bloom e Van Reenen (2006) desenvolveram um método para realizar esse tipo de mensuração e o aplicaram em 732 empresas manufatureiras nos Estados Unidos, França, Alemanha e Reino Unido e anos após (Bloom \& Van Reenen, 2010) expandiram e aperfeiçoaram esse método aplicando-o em quase 6.000 empresas espalhadas por mais países. O sistema de aferição desenvolvido pelos autores contempla os métodos qualitativo e quantitativo, tendo eles utilizado para este último técnicas econométricas. As dimensões e as variáveis utilizadas pelos autores para medir a qualidade da gestão podem ser observadas na Tabela 2, abaixo.

Tabela 2. Boas práticas de gestão - variáveis.

\begin{tabular}{cl}
\hline Operações & $\begin{array}{l}\text { Utilização de técnicas de lean manufacturing; racionalidade dos processos decisórios; documentação } \\
\text { de desvios; avaliação de performance; revisão periódica de performance; qualidade das reuniões de } \\
\text { performance; ações sobre resultados. }\end{array}$ \\
Performance & $\begin{array}{l}\text { Utilização de objetivos financeiros e não financeiros; clareza nos objetivos; distribuição dos mesmos; grau } \\
\text { de dificuldade para atingimento; conhecimento por todos; escala de tempo. }\end{array}$ \\
Incentivos & $\begin{array}{l}\text { Programas de bônus; ações sobre performance; políticas de promoção; identificação das pessoas com as } \\
\text { políticas da empresa; políticas de atração e retenão de talentos. }\end{array}$ \\
\hline
\end{tabular}

Nota. Elaborado pelos autores a partir de: Bloom, N., \& Van Reenen, J. (2006). Measuring and explaining management practices across firms and countries [CEP Discussion Paper No. 716]. Centre for Economic Performance, London, United Kingdom; Bloom, N., Van Reenen, J. (2007). Measuring and explaining management practices across firms and countries. The Quarterly Journal of Economics, 122(4), 1351-1408. https://doi.org/10.1162/ qjec.2007.122.4.1351; Bloom, N., \& Van Reenen, J. (2010). Why do management practices differ across firms and countries? Journal of Economic Perspectives, 24(1), 203-224. https://doi.org/10.1257/jep.24.1.203 
Observa-se que os autores elencaram três dimensões principais para medir a qualidade da gestão, sendo esta dividida em operações, performance e incentivos. Para cada uma delas, foram contempladas diversas variáveis, com pode ser observado na Tabela 2, acima.

O principal resultado observado pelos autores indicou que as práticas gerenciais adotadas pelas firmas são fortemente associadas com o nível de produtividade e lucratividade. Tal instrumento foi nomeado por eles como "melhores práticas de gestão", e a fim de adaptá-lo ao contexto brasileiro, a exemplo do que foi feito por Feldmann et al. (2019), optou-se neste trabalho por utilizar a expressão "boas práticas de gestão". Apesar de aceito o instrumento desenvolvido por Bloom e Van Reenen (2010), ele não deixa de sofrer algumas críticas. Agarwal et al. (2014) comentam a limitação deste instrumento por não considerar algumas dimensões importantes, como: gerenciamento do conhecimento, gerenciamento do relacionamento, gerenciamento da tecnologia e gerenciamento estratégico, os quais deveriam também ser relacionados com as práticas de gestão de empresas manufatureiras.

Por outro lado, Maloney e Sarrias (2014) confirmam as revelações das pesquisas de Bloom e Van Reenen (2007), reforçando que variáveis como a estrutura de propriedade das empresas e a dimensão do capital humano são essenciais à boa gestão.

Para corroborar os pontos anteriores e avançar no entendimento, Bloom et al. (2019) estenderam seu estudo para 35.000 plantas industriais e verificaram que fatores exógenos como altos níveis de capital humano e competição entre os setores estão também associados com scores de melhores práticas de gestão.

Além disso, Wu (2015) e Wiengarten, Gimenez, Fynes e Ferdows (2015) comentam que uma organização deve primeiro construir sua cultura alinhadamente aos seus objetivos para depois realizar benchmarking com as práticas de seus concorrentes bem-sucedidos. Nesse sentido, a atitude, o comportamento, a prioridade e as crenças das pessoas são essenciais para conduzir as decisões táticas que impactam a estratégia.

De maneira geral, os estudos de Bloom e Van Reenen (2006, 2007, 2010) apresentam uma série de eventos que contribuem para que a gestão deficitária persista, principalmente em função de os mercados serem imperfeitos. São apresentadas abaixo algumas de suas considerações: a. Empresas com melhores práticas de gestão tendem a ser maiores, mais produtivas, crescem mais rapidamente, e têm maiores taxas de sobrevivência.

b. Há diferenças significativas de práticas de gestão entre os países. Por exemplo, enquanto nos Estados Unidos uma parcela pequena de firmas se situa na faixa de mau gerenciamento, no Brasil e Índia há um número grande de empresas nessa faixa.

c. Multinacionais são geralmente mais bem geridas nos países em que estão instaladas do que as firmas nacionais.

d. Empresas que apontam um membro da família (especialmente o filho mais velho) como chefe executivo são na média muito mal gerenciadas.

e. Empresas estatais são em geral mal gerenciadas, ao passo que quando essas empresas possuem como acionistas fundos de pensão os resultados são melhores.

\section{METODOLOGIA}

A fim de responder às questões de pesquisa, este trabalho segue um método exploratório explicativo, pois a dinâmica que se pretendeu investigar refere-se a uma dinâmica do mundo exterior (Angrosino, 2009; Godoy, 2006). É exploratório porque se busca entender as possíveis relações entre boas práticas de gestão, a capacidade absortiva e seus efeitos sobre a produtividade. Já a estratégia utilizada foi a de estudo multicasos, que, segundo Eisenhardt (1989), permite que se construam teorias acerca de fenômenos pouco conhecidos.

Para dar conta do intento relacionado às questões de pesquisa, foram eleitas três empresas transnacionais e duas nacionais com operação no Brasil do ramo de embalagens plásticas, as quais se situam na categoria de média-baixa intensidade tecnológica. Como observado por Feldmann (2009), há muitas empresas de baixa e média intensidade tecnológica situadas no Brasil, e ao se escolher empresas desta classificação, pode-se revelar um pouco da dinâmica no país acerca das variáveis estudadas.

As unidades de análise nessas empresas serão os departamentos de P\&D e de gestão. As empresas são detalhadas na Tabela 3, a seguir. 
Tabela 3. Caracterização das empresas.

\begin{tabular}{|c|c|}
\hline Empresa & Característica/Singularidade \\
\hline Alpha & $\begin{array}{l}\text { Fundada em Portugal, mas pertence atualmente a um grupo norte-americano. Está presente em } 16 \text { países, com } 59 \\
\text { plantas industriais. Mantém filial no Brasil e possui forte penetração de mercado. A empresa inovou no modelo } \\
\text { organizacional ao instalar suas plantas dentro das instalações de seus clientes, reduzindo drasticamente o custo de } \\
\text { suas operações. Tal inovação foi decorrente da pressão de mercado por custos menores em funça do acirramento } \\
\text { da concorrência. }\end{array}$ \\
\hline Beta & $\begin{array}{l}\text { Empresa norte-americana, presente nos continentes americano, europeu e asiático, conta com } 95 \text { fábricas. Possui } \\
\text { filial no Brasil. Sua principal inovação foi a criação de uma máquina que elevou a produtividade em } 18 \text { vezes, } \\
\text { tornando-se benchmarking mundial. Tal feito ocorreu em decorrência da necessidade de a empresa diminuir custos } \\
\text { operacionais. }\end{array}$ \\
\hline Gama & $\begin{array}{l}\text { Empresa norte-americana, contando com } 18.000 \text { funcionários e } 60 \text { fábricas espalhadas por } 12 \text { países, sendo } \\
\text { considerada a maior empresa de embalagens flexíveis das Américas e a maior indústria de materiais sensiveis à } \\
\text { pressão. No Brasil, conta com } 5.000 \text { funcionários distribuídos em quatro fábricas. Possui diversos cientistas PhDs } \\
\text { alocados na matriz, tendo desenvolvido diversas inovações de produtos. Há, portanto, uma orientação na própria } \\
\text { cultura organizacional para que a empresa se mantenha diferenciada em relação aos concorrentes. }\end{array}$ \\
\hline Sigma & $\begin{array}{l}\text { Tradicional empresa brasileira com } 30 \text { anos de atuação, contando com uma unidade industrial e } 400 \text { funcionários. } \\
\text { A empresa apresenta-se como uma das líderes no segmento de atuação. Conta com um laboratório de P\&D e divulga } \\
\text { em seu ambiente institucional as suas ações de inovação, sendo estas realizadas em função de demandas de clientes. }\end{array}$ \\
\hline Zeta & $\begin{array}{l}\text { Tradicional empresa brasileira, fundada na década de } 1980 \text {. Conta com sete unidades industriais em diversos } \\
\text { estados brasileiros e recebe constantemente prêmios de inovação por suas embalagens. Essas inovações ocorrem } \\
\text { por demandas de clientes. }\end{array}$ \\
\hline
\end{tabular}

Nota. Elaborado pelos autores.

A coleta de dados deu-se em duas fases:

$\mathbf{1}^{\mathbf{a}}$ fase: Inicialmente se privilegiou a realização das entrevistas em um mesmo número de empresas estrangeiras com subsidiárias no Brasil e empresas nacionais. Contudo, em função da dificuldade de encontrar empresas brasileiras que possuíssem algumas singularidades, como, por exemplo, forte presença de mercado ou direcionamento para atividades inovativas, limitou-se a apenas duas.

Essas empresas se situam no ramo específico de embalagens plásticas, fornecedoras para as indústrias de alimentos, cosméticos, bebidas e farmacêuticos. Este segmento foi escolhido em função do critério de conveniência; contudo, as empresas escolhidas possuem reconhecimento do mercado por sua trajetória ascendente e pelas políticas de inovação, o que pôde ser confirmado anteriormente em relatório técnico do setor (Abiplast, 2015).

Quanto às entrevistas, estas seguiram um roteiro semiestruturado e foram aplicadas em 15 executivos (três para cada empresa) que ocupam cargos de direção e gerência, especificamente das áreas de P\&D, operações e gestão. No caso do elemento de análise capacidades absortivas, buscouse entender a rotina de busca de conhecimento externo e como este é tratado dentro da organização, como pode ser observado por meio da Tabela 4 .

Tabela 4. Pontos mapeados no trabalho de campo na dimensão capacidade absortiva.

\begin{tabular}{|c|c|c|}
\hline \multirow{2}{*}{$\begin{array}{l}\text { Capacidade Absortiva } \\
\text { Potencial }\end{array}$} & Aquisição & $\begin{array}{l}\text { As formas e meios pelos quais a empresa busca o conhecimento externo; maneira pela } \\
\text { qual os funcionários buscam e lidam com a informação dentro e além da indústria; } \\
\text { parcerias estabelecidas com fornecedores, universidades, clientes e redes de negócios; } \\
\text { relacionamento das filiais (multinacionais) com suas matrizes. }\end{array}$ \\
\hline & Assimilação & $\begin{array}{l}\text { Processos e rotinas que permitem que a nova informação seja analisada, processada, } \\
\text { interpretada e classificada na empresa; fluxo de informações entre os departamentos; } \\
\text { distribuição do novo conhecimento. }\end{array}$ \\
\hline \multirow{2}{*}{$\begin{array}{l}\text { Capacidade Absortiva } \\
\text { Realizada }\end{array}$} & Transformação & $\begin{array}{l}\text { Formas pela qual a empresa estrutura o novo conhecimento e como este conecta as } \\
\text { velhas rotinas com as que podem surgir como novas ou adaptadas. }\end{array}$ \\
\hline & Aplicações & $\begin{array}{l}\text { Implantação de novas rotinas que surgem como resultado do processo de transformação, } \\
\text { ou, então, rotinas antigas que são readaptadas e aplicadas nas rotinas já existentes, que } \\
\text { deem vazão a novas tecnologias por parte da organização. }\end{array}$ \\
\hline
\end{tabular}

Nota. Elaborado pelos autores por meio da revisão de literatura. 
Além disso, verificou-se nas empresas o modo pelo qual os mecanismos de ativação influenciam o início do processo de capacidade absortiva potencial (aquisição e assimilação) e os mecanismos de integração social em relação à capacidade absortiva realizada (transformação e aplicação).

Já no que se refere aos elementos relativos às boas práticas de gestão, as entrevistas foram conduzidas tendo como base o questionário desenvolvido por Bloom e Van Reenen $(2006,2007)$ e aperfeiçoado na sua pesquisa em 2010 (Bloom \& Van Reenen, 2010), estando estas variáveis apresentadas na Tabela 2, acima, na seção "Boas práticas de gestão". Cabe frisar que o instrumento original possui elementos qualitativos e quantitativos, de modo que, para esta pesquisa, adaptou-se o instrumento qualitativo.

Após a realização das entrevistas estruturadas de acordo com as dimensões constantes da Tabela 2 , que foram gravadas com permissão, elas foram transcritas e analisadas. A análise deu-se por meio da técnica de análise de conteúdo, que para Mozzato e Grzybovski (2011) apresenta-se como um importante instrumento para a pesquisa qualitativa no campo da Administração. Para dar suporte e facilitar a categorização dos dados, foi ainda utilizado o software NVivo. Adicionalmente, foram pesquisados dados em fontes secundárias a fim de gerar triangulação entre as informações e reforçar as análises.

$2^{\mathbf{a}}$ fase: Nesta fase da coleta de dados primários buscou-se trazer elementos que possibilitassem a mensuração da evolução do índice de produtividade das empresas. A depender da disposição da empresa em fornecer tais dados, já que muitos deles possuem caráter estratégico, utilizou-se de formas não padronizadas entre as empresas para se medir este indicador, mas ressaltando que todas as que foram utilizadas são previstas no manual da organização para cooperação e desenvolvimento econômico (Organisation for Economic Co-operation and Development [OECD], 2001) para o cálculo de produtividade.

A primeira opção foi a de calcular com base na produtividade total dos fatores (PTF), o que pode ser conseguido por meio da função Cobb-Douglas. Esta seria uma maneira mais precisa de calcular a produtividade, já que neste método consegue-se anular o efeito de trade-off entre a substituição de funcionários por tecnologia. Na segunda opção, buscou-se o cálculo da razão entre produção total (em toneladas) e número de funcionários, sendo este método também conhecido como o de produtividade do trabalho. E a última opção considerou a produtividade como sendo decorrente do valor adicionado (receitas líquidas - custos de produção) em razão de alguma medida de funcionários, como salários ou número de pessoal ocupado na empresa (OECD, 2001).

Na colheita dessas informações, infelizmente não se conseguiu as mesmas informações para as cinco empresas, já que elas alegaram segredo estratégico. Assim, a única informação que de fato pôde ser comparada é a relativa ao cálculo da produtividade do trabalho, podendo, ao menos, gerar um padrão único de comparação. O período utilizado para este cálculo foi de cinco anos, entre 2013 e 2017.

\section{APRESENTAÇÃO DOS RESULTADOS}

A fim de facilitar a apresentação dos resultados, descrever-se-á em forma de tabelas as principais características por empresa nas variáveis estudadas, sendo divididos em dois grupos: as subsidiárias estrangeiras e as nacionais. Apresentase por meio da Tabela 5 as características das empresas transnacionais.

Ao se analisar a Tabela 5, acima, algumas observações podem ser feitas:

- Nas três empresas há uma cultura de gestão implantada. Ainda que existam variações na forma como elas se enquadram nas dimensões de gestão, elas procuram seguir processos racionais de técnicas de gerenciamento.

- Em Alpha e Gama, é evidenciada a cultura de inovação. Embora a filial brasileira de Beta esteja afastada temporariamente das atividades de inovação, essa importância é reconhecida, de forma que estão buscando alternativas para retomar essas atividades.

- No que se refere às atividades de P\&D, todas as três empresas são dependentes em alto grau das políticas de inovação originárias nas suas matrizes no exterior.

- Nas três empresas, em decorrência da própria rotina de gestão, ainda que subordinada às diretrizes das suas matrizes, consegue-se desenvolver mecanismos de integração social. Isto é observado, sobretudo, no papel dos líderes, que reúnem suas equipes e as preparam, motivando-as e cobrando-as por resultados. Dessa forma, há um caminho natural em que se avança com mais facilidade entre as fases de assimilação (capacidade absortiva potencial) e transformação (capacidade absortiva realizada). Em outras palavras, o conhecimento externo passa a ser internalizado no modus operandi dessas empresas. 
Tabela 5. Síntese dos resultados verificados nas empresas subsidiárias estrangeiras com presença no Brasil.

\begin{tabular}{|c|c|c|c|c|}
\hline & & \multirow[b]{2}{*}{ Alpha } & \multirow[b]{2}{*}{ Beta } & \multirow[b]{2}{*}{ Gama } \\
\hline & & & & \\
\hline \multirow{2}{*}{$\begin{array}{l}\text { Capa- } \\
\text { cidade } \\
\text { Absortiva } \\
\text { Potencial }\end{array}$} & Aquisição & $\begin{array}{l}\text { O conhecimento é adquirido e } \\
\text { desenvolvido em sua totalidade } \\
\text { nas centrais de P\&D no exterior. } \\
\text { Nesse caso, a subsidiária brasileira } \\
\text { é totalmente dependente desse } \\
\text { conhecimento externo. }\end{array}$ & $\begin{array}{l}\text { A busca de conhecimento é centrada } \\
\text { totalmente nas matrizes nos } \\
\text { Estados Unidos e Itália. Por decisão } \\
\text { estratégica da holding, a operação no } \\
\text { Brasil, temporariamente, não poderá } \\
\text { desenvolver nenhum produto novo, } \\
\text { até que investimentos anteriores } \\
\text { sejam recuperados do ponto de vista } \\
\text { financeiro. }\end{array}$ & $\begin{array}{l}\text { A empresa possui um centro de } \\
\text { P\&D na matriz nos Estados Unidos, } \\
\text { de onde mantém programas de } \\
\text { treinamentos e alinhamentos com as } \\
\text { diversasunidades de P\&D espalhadas } \\
\text { pelo mundo. Essas informações } \\
\text { derivam, além do trabalho interno } \\
\text { de PhDs, da interação da empresa } \\
\text { com fornecedores, clientes, } \\
\text { universidades e centros de pesquisa. }\end{array}$ \\
\hline & Assimilação & $\begin{array}{l}\text { Após os conhecimentos serem } \\
\text { absorvidos do exterior, eles são } \\
\text { internalizados; no entanto, não } \\
\text { são assimilados de forma dinâmica } \\
\text { entre os departamentos. Observa- } \\
\text { se em certa medida que há uma } \\
\text { centralização da informação em } \\
\text { poucos líderes. }\end{array}$ & $\begin{array}{l}\text { A equipe de gestores no Brasil se } \\
\text { reune frequentemente a fim de } \\
\text { discutir tendências do mercado, } \\
\text { inovações e desempenho da } \\
\text { empresa como um todo. São } \\
\text { tratadas melhorias que poderão } \\
\text { ser incorporadas nos processos } \\
\text { produtivos, gerando melhorias em } \\
\text { produtos. }\end{array}$ & $\begin{array}{l}\text { A empresa mantém um programa de } \\
\text { rodízio de funcionários das diversas } \\
\text { plantas do mundo, trabalhando } \\
\text { em período temporário na matriz } \\
\text { de P\&D. Essa rotina permite maior } \\
\text { fluxo de informações e assimilação } \\
\text { de conhecimentos. Além disso, } \\
\text { são realizadas reuniões diárias ou } \\
\text { semanais entre os times. }\end{array}$ \\
\hline \multirow{2}{*}{$\begin{array}{l}\text { Capacida- } \\
\text { de Absor- } \\
\text { tiva Reali- } \\
\text { zada }\end{array}$} & Transformação & $\begin{array}{l}\text { Os novos conhecimentos advindos } \\
\text { do exterior são considerados a fim } \\
\text { de serem incorporados às práticas } \\
\text { organizacionais. Isso se dá com o } \\
\text { apoio de um sistema de gestão que } \\
\text { alinha todos os funcionários. }\end{array}$ & $\begin{array}{l}\text { Os gerentes, juntamente com } \\
\text { seus times, consideram novas } \\
\text { informações de modo a transformar } \\
\text { e readaptar as rotinas que precisam } \\
\text { ser reelaboradas. }\end{array}$ & $\begin{array}{l}\text { Novas rotinas advindas do exterior } \\
\text { são facilmente incorporadas, } \\
\text { readaptadas, e geram novas } \\
\text { rotinas. Em alguns casos, essa } \\
\text { transformação esbarra no limite } \\
\text { da operação dos clientes, que } \\
\text { não conseguem modificar suas } \\
\text { estruturas produtivas em função de } \\
\text { altos custos de implantação. }\end{array}$ \\
\hline & Aplicação & $\begin{array}{l}\text { Os novos conhecimentos são } \\
\text { adaptados facilmente na empresa, } \\
\text { modificando rotinas quando } \\
\text { necessário. }\end{array}$ & $\begin{array}{l}\text { Apesar de a empresa considerar } \\
\text { novas informações a fim de } \\
\text { transformar suas rotinas e aplicá- } \\
\text { las, muitas melhorias esbarram na } \\
\text { limitação estratégica imposta pela } \\
\text { matriz à filial brasileira. }\end{array}$ & $\begin{array}{l}\text { Os novos conhecimentos são } \\
\text { adaptados e implantados na } \\
\text { organização, apoiados por um } \\
\text { processo de gestão que controla } \\
\text { todas as inovações. }\end{array}$ \\
\hline \multirow{3}{*}{$\begin{array}{l}\text { Práticas de } \\
\text { gestão }\end{array}$} & Operação & $\begin{array}{l}\text { Possui controle de toda a operação } \\
\text { por meio de KPIs. Há um sistema } \\
\text { de metas que abrange todos os } \\
\text { funcionários e estes são medidos } \\
\text { por meio delas. Para os funcionários } \\
\text { que não atingem metas, é elaborado } \\
\text { plano de treinamento visando à sua } \\
\text { recuperação. }\end{array}$ & $\begin{array}{l}\text { A empresa não possui um sistema de } \\
\text { lean manufacturing implantado em } \\
\text { todos os países, e na filial brasileira } \\
\text { também não está implantado. } \\
\text { Os resultados são medidos } \\
\text { periodicamente, e funcionáriós } \\
\text { que não atingem resultados, após } \\
\text { treinamentos específicos, são } \\
\text { desligados da empresa. }\end{array}$ & $\begin{array}{l}\text { A empresa adota práticas de } \\
\text { manufatura enxuta de forma } \\
\text { padronizada em todas as plantas } \\
\text { ao redor do mundo. Diariamente, } \\
\text { há reuniões entre a supervisão e } \\
\text { seus times para alinhar os objetivos } \\
\text { e resultados. Problemas de } \\
\text { performance não são tão sentidos } \\
\text { pela empresa, pois as reuniões } \\
\text { diárias servem para corrigir erros e } \\
\text { alcançar resultados. }\end{array}$ \\
\hline & Performance & $\begin{array}{l}\text { Existem objetivos financeiros e não } \\
\text { financeiros, sendo desdobrados } \\
\text { para todos os níveis. Há cobrança } \\
\text { rotineira destes objetivos, gerando } \\
\text { competição interna entre os } \\
\text { departamentos, o que alimenta, } \\
\text { inclusive, critérios de promoção. }\end{array}$ & $\begin{array}{l}\text { Os objetivos financeiros e não } \\
\text { financeiros são desdobrados } \\
\text { mundialmente até o nível de } \\
\text { supervisão de cada filial. Os objetivos } \\
\text { orientam as ações individuais dos } \\
\text { funcionários. São gerenciadas metas } \\
\text { de curto, médio e longo prazo. }\end{array}$ & $\begin{array}{l}\text { As metas estão alinhadas com o } \\
\text { plano de longo prazo da empresa, } \\
\text { sendo distribuídas por todas as } \\
\text { plantas e alcançando todos os } \\
\text { níveis. De modo geral, não são } \\
\text { fáceis de serem atingidas; contudo, } \\
\text { motivam os funcionários em função } \\
\text { do sistema de premiação atrelado a } \\
\text { esse sistema. }\end{array}$ \\
\hline & Incentivos & $\begin{array}{l}\text { Apesar de não haver um sistema } \\
\text { de bônus que premie boas } \\
\text { performances, estas alimentam o } \\
\text { radar de promoção de funcionários. }\end{array}$ & $\begin{array}{l}\text { A empresa mantém um plano de } \\
\text { treinamento mundial para atração de } \\
\text { talentos. Embora não possua plano } \\
\text { de carreira formal, os funcionários } \\
\text { são remunerados com bônus em } \\
\text { vista de resultados alcançados. }\end{array}$ & $\begin{array}{l}\text { A empresa possui um sistema } \\
\text { de controle de atingimento de } \\
\text { resultados e metas contempladas no } \\
\text { programa de pagamento de bônus. } \\
\text { A fim de buscar maior eficácia, a } \\
\text { empresa procura ser criteriosa na } \\
\text { seleção e contratação de talentos. }\end{array}$ \\
\hline \multirow{5}{*}{ Resultados } & \multirow{5}{*}{ Produtividade } & $\begin{array}{l}\text { A empresa apresentou aumento } \\
\text { de produtividade acumulado de } \\
67,02 \% \text { entre os anos de } 2013 \text { e } \\
2017 \text {. }\end{array}$ & $\begin{array}{l}\text { Nos anos acumulados entre } \\
2013 \text { e } 2017 \text {, houve aumento da } \\
\text { produtividade em } 37,22 \% \text {. }\end{array}$ & $\begin{array}{l}\text { A empresa apresentou crescimento } \\
\text { acumulado da produtividade de } \\
7,35 \% \text { entre os anos de } 2013 \text { e } 2017 \text {. }\end{array}$ \\
\hline & & $201+2-2$ & $2013 \rightarrow 2014:-1,08 \%$ & $2013 \rightarrow 2014: 1,38 \%$ \\
\hline & & $2014 \rightarrow 2015: 35,53 \%$ & $\begin{array}{l}1,16 \% \\
4,03 \%\end{array}$ & $2014 \rightarrow 2015:$ 6,91\% \\
\hline & & $2015 \rightarrow 2016: 0,77 \%$ & $\begin{array}{l}:-4,03 \% \\
: 21,17 \%\end{array}$ & $\begin{array}{l}2015 \rightarrow 2016:-4,33 \% \\
2016 \rightarrow 2017 \cdot 3,39 \%\end{array}$ \\
\hline & & $2016 \rightarrow 2017: 29,61 \%$ & 201082011.21 & 我 \\
\hline
\end{tabular}

Nota. Elaborado pelos autores. 
Outro ponto que merece ser observado consta na Tabela 3. No caso das empresas transnacionais, a motivação para a tarefa de inovação decorre de desafios que se apresentaram à sua própria sobrevivência, ou seja, por meio de mecanismos de ativação. No caso de Alpha, foi a instalação de suas plantas dentro das áreas fabris dos clientes. No caso de Beta, foi a invenção de um mecanismo que aumentou a produtividade da tecnologia de sopro de plásticos em dezoito vezes. E no caso de Gama, foi a determinação da empresa em se manter à frente de seus concorrentes.

De maneira geral, pode-se inferir que a cultura dessas empresas, no que concerne às práticas de gestão e busca de conhecimento externo para aperfeiçoar as atividades de inovação, gera resultados positivos em termos de produtividade, o que pode ser observado nas três empresas devido ao seu crescimento acumulado (Alpha: 67,02\%; Beta: 37,22\%; Gama: 7,35\%). Frisa-se aqui que o resultado superior de Alpha, segundo os gestores entrevistados, justifica-se por uma transformação radical do processo de gestão nos últimos anos, inclusive com o acompanhamento de uma consultoria externa.

No caso das empresas brasileiras, os resultados são apresentados na Tabela 6 .

Tabela 6. Síntese dos resultados verificados nas empresas brasileiras.

\begin{tabular}{|c|c|c|c|}
\hline & & \multirow[b]{2}{*}{ Sigma } & \multirow[b]{2}{*}{ Zeta } \\
\hline & & & \\
\hline $\begin{array}{l}\text { Capacidade } \\
\text { Absortiva } \\
\text { Potencial }\end{array}$ & Aquisição & $\begin{array}{l}\text { A política de inovação é voltada para as } \\
\text { demandas dos clientes. O P\&D é reativo, atuando } \\
\text { principalmente para adaptar nos equipamentos } \\
\text { da empresa a produção dessas demandas. Todo } \\
\text { esforço inovativo é direcionado para melhorias } \\
\text { incrementais nas linhas de produtos. Outra face } \\
\text { da aquisição de conhecimentos é a decorrente da } \\
\text { compra de máquinas, que gera treinamentos aos } \\
\text { envolvidos na operação. }\end{array}$ & $\begin{array}{l}\text { O conhecimento novo da empresa é concentrado } \\
\text { no departamento de engenharia de embalagens, } \\
\text { que age, sobretudo, na funcionalidade das } \\
\text { máquinas para que adaptem produtos novos } \\
\text { à produção, visando a maiores índices de } \\
\text { produtividade. }\end{array}$ \\
\hline & Assimilação & $\begin{array}{l}\text { O conhecimento advindo do intercâmbio com os } \\
\text { clientes ou então junto aos fornecedores relativos } \\
\text { aos equipamentos adquiridos pela empresa fica } \\
\text { circunscrito aos departamentos envolvidos na } \\
\text { operação. }\end{array}$ & $\begin{array}{l}\text { O conhecimento novo, principalmente o } \\
\text { decorrente da aquisição de novas máquinas, fica } \\
\text { limitado às pessoas envolvidas na operação. }\end{array}$ \\
\hline \multirow[t]{2}{*}{$\begin{array}{l}\text { Capacidade } \\
\text { Absortiva } \\
\text { Realizada }\end{array}$} & Transformação & $\begin{array}{l}\text { As mudanças em termos de rotinas não são } \\
\text { expressivas para além dos departamentos } \\
\text { envolvidos. As mudanças são decorrentes da } \\
\text { própria dependência tecnológica em torno dos } \\
\text { equipamentos que a empresa utiliza. }\end{array}$ & $\begin{array}{l}\text { As modificações de padrões e rotinas são pouco } \\
\text { expressivas na empresa. Mesmo havendo alguns } \\
\text { projetos desenvolvidos juntamente com clientes, } \\
\text { estes não geram mudanças nas rotinas da } \\
\text { empresa. }\end{array}$ \\
\hline & Aplicação & $\begin{array}{l}\text { Mediante a própria característica de a empresa } \\
\text { concentrar os novos conhecimentos nas áreas } \\
\text { produtivas, ela pouco transforma e explora os } \\
\text { potenciais de melhorias que se apresentam. }\end{array}$ & $\begin{array}{l}\text { Em função de a empresa adotar uma prática de } \\
\text { inovação centrada na troca de equipamentos, ela } \\
\text { pouco transforma suas rotinas e práticas. }\end{array}$ \\
\hline \multirow[t]{3}{*}{$\begin{array}{l}\text { Práticas de } \\
\text { gestão }\end{array}$} & Operação & $\begin{array}{l}\text { A empresa segue parâmetros operacionais dentro } \\
\text { das normas impostas pelos certificados de } \\
\text { acreditação, como, por exemplo, o certificado ISO } \\
9001 \text {. }\end{array}$ & $\begin{array}{l}\text { Além da certificação ISO 9001-2008 implantada, } \\
\text { a empresa mantém o sistema SAP para integrar } \\
\text { as operações, sendo que a existência deste é } \\
\text { reconhecida como de extrema importância para } \\
\text { assegurar a padronização das operações. }\end{array}$ \\
\hline & Performance & $\begin{array}{l}\text { Há números gerais como, por exemplo: metas } \\
\text { de faturamento, metas de captação de clientes, } \\
\text { metas de desperdício, metas gerais de qualidade, } \\
\text { metas de satisfação de clientes, dentre outras. } \\
\text { Essas são desenhadas uma vez por ano no mês } \\
\text { de janeiro. }\end{array}$ & $\begin{array}{l}\text { Os números de faturamento são alocados de forma } \\
\text { geral por departamento. Após a definição destes } \\
\text { números, anualmente, estes são distribuídos por } \\
\text { todos os departamentos em todas as fábricas, } \\
\text { ficando limitados à esfera gerencial. }\end{array}$ \\
\hline & Incentivos & $\begin{array}{l}\text { A empresa aplica um sistema de participação nos } \\
\text { lucros limitada à exigência da legislação vigente. } \\
\text { As metas são gerais, mas não individualizadas, } \\
\text { o que não permite atrelar remuneração ao } \\
\text { desempenho. }\end{array}$ & $\begin{array}{l}\text { A remuneração por desempenho não ocorre } \\
\text { para todos os níveis, apenas para os gerentes e } \\
\text { diretores. }\end{array}$ \\
\hline \multirow[t]{5}{*}{ Resultados } & Produtividade & $\begin{array}{l}\text { A produtividade acumulada da empresa entre os } \\
\text { anos de } 2013 \text { e } 2017 \text { apresentou diminuição de } \\
\mathbf{0 , 6 6 \%} \text {. }\end{array}$ & $\begin{array}{l}\text { A produtividade acumulada da empresa entre os } \\
\text { anos de } 2013 \text { e } 2017 \text { apresentou diminuição de } \\
7,59 \% \text {. }\end{array}$ \\
\hline & & $2013 \rightarrow 2014:-0,24 \%$ & $2013 \rightarrow 2014:-2,74 \%$ \\
\hline & & $2014 \rightarrow 2015:-2,76 \%$ & $2014 \rightarrow 2015:-2,71 \%$ \\
\hline & & $2015 \rightarrow 2016: 3,76 \%$ & $2015 \rightarrow 2016:-0,43 \%$ \\
\hline & & $2016 \rightarrow 2017:-1,42 \%$ & $2016 \rightarrow 2017:-2,57 \%$ \\
\hline
\end{tabular}

Nota. Elaborado pelos autores. 
Ao se analisar o quadro acima, algumas observações são realizadas:

- As duas empresas, Sigma e Zeta, restringem suas atividades de busca de novos conhecimentos baseadas na aquisição de máquinas e/ou quando surgem demandas de clientes.

- Os departamentos de P\&D não possuem atividades de pesquisas e são circunstanciados à área produtiva na adaptação de produtos aos processos fabris. Este fato é corroborado por Feldmann (2009) e Ledereman, Messina, Pienknagura e Rigolini (2014), ao comentarem sobre as baixas taxas de inovação de empresas latino-americanas.

- Sigma e Zeta adotam processos de gestão em função do que é direcionado pelas normas de acreditação, como, por exemplo, a ISO 90012008.

- Nas duas empresas, os mecanismos de integração social ocorrem em níveis muito pequenos, o que desagrega os funcionários e dispersa o foco quanto aos resultados. Por exemplo, os gestores concentram em si as informações importantes, não as disseminando entre os seus liderados e tampouco promovendo a troca de informações ou circulação destas na empresa por outros mecanismos de circulação.

Cabe destacar que nas empresas nacionais, conforme consta da apresentação das empresas na Tabela 3, os mecanismos de ativação da busca por conhecimentos externos se limitam apenas às demandas de clientes, não havendo nenhuma outra situação de mercado (como uma crise ou intenção de diferenciar-se) que impulsiona estas empresas a inovar.

Ademais, a cultura de gestão dessas empresas poucocontribuiparaque elas absorvam conhecimento externo relevante, o qual poderia impulsionar o processo de inovação e, consequentemente, levar ao aumento da produtividade. Tal constatação é refletida na queda de produtividade acumulada entre os anos de 2013 e 2017 para as duas empresas nacionais (Sigma: -0,66\%; Zeta: -7,59\%).

Essas são algumas constatações de caráter mais genérico dos dois grupos de empresas. Outras questões são discutidas na seção seguinte.

\section{DISCUSSÃO DOS RESULTADOS}

A literatura acadêmica, bem como publicações de órgãos oficiais de governos que tratam de assuntos relativos à gestão (Agarwal et al., 2014; Bloom \& Van Reenen, 2010; Feldmann et al., 2019; Ledereman et al., 2014) e os números que retratam os esforços de inovação, normalmente associam os bons resultados aos países desenvolvidos. Dessa forma, a pesquisa de campo realizada neste trabalho, que combina boas práticas de gestão com capacidade absortiva e os efeitos sobre a produtividade, possibilita algumas reflexões.

No que se refere à capacidade absortiva por parte das empresas transnacionais, observou-se que elas recebem o conhecimento de que necessitam diretamente das suas matrizes, como observado por Bertrand e Mol (2013), que associam essa situação à abundância de recursos presente nos locais onde elas mantêm seus quarteis generais. No exterior, normalmente em países em desenvolvimento, esse conhecimento está baseado num forte processo de atividades de P\&D reforçado pela interação com outros órgãos de pesquisa como universidades, centros de pesquisa e fornecedores. Wang e Han (2011), Müller-Seitz e Güttel(2014) e Cohen e Levinthal (1990) enaltecem esse tipo de comportamento para o fortalecimento da capacidade absortiva.

No caso das empresas brasileiras, o conhecimento novo é resultante da compra de equipamentos e da necessidade de aprendizado para operá-los ou da demanda unilateral de clientes. Conhecimentos novos oriundos de parceria com fornecedores, visitação a feiras e outros, conforme sugerido por Nonaka e Takeuchi (1995), poderiam gerar estímulos e insights às empresas nacionais, os quais ampliariam o horizonte de conhecimento da organização. Nesse sentido, pode-se dizer também que, no caso das empresas de capital brasileiro, os mecanismos de ativação - aqueles que orientam a empresa a iniciar seu processo de busca por novos conhecimentos (Zahra \& George, 2002) - falham, já que se limitar às demandas de clientes para tentar inovar torna muito frágeis as estratégias competitivas por parte dessas empresas.

Nas empresas nacionais, por não haver rotinas tão presentes quanto à aquisição e assimilação do conhecimento externo (capacidade absortiva potencial), tanto a fase de transformação quanto a de aplicação do conhecimento externo (capacidade absortiva realizada) ficam prejudicadas. Ademais, apresentou-se nas empresas a falta de mecanismos de integração social. A presença desses estímulos reforçaria a coesão social entre os funcionários e entre os líderes e seus subordinados, promovendo uma rotina de aprendizagem e de cooperação para a implantação de novas ideias (Morano, Barrichello, \& Jacomossi, 2016; Vega-Jurado, Gutiérrez-Gracia, \& Fernández-de-Lucio, 2008; Zahra \& George, 2002).

Por outro lado, para as empresas transnacionais, observa-se um esforço nas rotinas gerenciais para o reforço dos padrões estabelecidos, como, por exemplo, na alta periodicidade com que são realizadas reuniões entre os líderes e seus 
grupos, ou em práticas de rodízio de funcionários em funções diferentes, reforçando, portanto, a importância desse mecanismo e denotando melhorias na distribuição de conhecimento e implantação de novas rotinas nas organizações (Armstrong \& Lengnick-Hall, 2013; Cuervo-Cazurra, 2017; Zahra \& George, 2002).

Com efeito, observa-se uma relação entre esses mecanismos de integração social e a própria tarefa de gestão, já que as rotinas estabelecidas nas organizações são em grande medida contempladas de modo formal nos desenhos dos seus processos. Assim, pode-se inferir que, havendo processos de boas práticas de gestão desenhados na organização, estes influem de modo positivo na capacidade absortiva. Esta posição é corroborada por Guimarães et al. (2016), os quais afirmam que em havendo um bom processo de gestão, a empresa adota padrões de comportamento que de forma indireta contribuem para o aumento do conhecimento advindo de fontes externas.

Especificamente em relação aos processos de gestão, observam-se disparidades entre as multinacionais e as nacionais no que tange às diversas dimensões. Na dimensão Operações, as empresas transnacionais adotam ferramentas para aplicação de conceitos de manufatura enxuta, com uma preocupação visível no que tange ao controle dos indicadores de desempenho. Já as empresas brasileiras limitam sua gestão na utilização de mecanismos de controle oriundos dos indicadores da norma ISO 9001-2008.

Na esfera relativa à dimensão da Performance, as multinacionais adotam critérios bem definidos de planejamento e distribuição de metas, em que se segue uma diretriz da matriz mundial. Esses números são desdobrados por plantas, por diretoria, por gerência e por supervisão, até chegar à base da organização, inclusive com bônus de desempenho atrelado ao seu atingimento. Já em relação às empresas brasileiras, os números são abertos de forma geral na forma de objetivos, ficando circunstanciados à diretoria e gerência, sendo contemplados e controlados a partir do sistema ISO.

No que se refere à dimensão Incentivos nas empresas brasileiras, essas firmas seguem como parâmetro a legislação trabalhista e os acordos sindicais para balizar o sistema de pagamentos de bônus aos funcionários. Esses não são referenciados pelo desempenho dos indicadores, mas sim por um valor fixo estipulado em lei, o que vai na contramão do que foi exposto por Phoocharoon (2015) e Wang, Zhao e Zhou (2018), que comentam que é indispensável ao desenvolvimento da capacidade absortiva a existência de incentivos oriundos do sistema de gestão que estimulem os funcionários a adquirir e promover novos conhecimentos a fim de gerar mudanças a partir deles.

Já as empresas transnacionais, no que se refere a este indicador, adotam critérios bem definidos de promoção de pessoas e atração/ retenção de talentos, mantendo planos de cargos e salários e políticas de promoção bem claros. Em países em desenvolvimento como o Brasil, em que há uma forte legislação trabalhista, as empresas, segundo Bloom e Van Reenen (2006, 2007), adotam poucos mecanismos de gestão voltados ao aumento da produtividade com base na motivação e engajamento dos colaboradores.

De acordo com o que foi abordado acima, tanto as práticas concernentes à capacidade absortiva quanto as de boas práticas de gestão diferem quando se compara as empresas transnacionais às firmas brasileiras. Isto repercute diretamente na evolução de produtividade das firmas, como pôde ser observado nas Tabelas 5 e 6 . No grupo das multinacionais, houve aumento da produtividade, enquanto nas empresas brasileiras $o$ índice declinou, considerando o período analisado. Este fato corrobora o que Bloom e Van Reenen (2006) e Maloney e Sarrias (2014) afirmam: no Brasil, há um número grande de empresas situadas na faixa longa de gestão precária, e isto é demonstrado por meio da baixa produtividade das empresas brasileiras participantes deste estudo.

Kim (2016) comenta que empresas oriundas de IDE (investimento direto estrangeiro) sentem melhor os efeitos das transferências de tecnologias sobre a produtividade dos seus negócios. O autor ainda vai além, afirmando que empresas nacionais poderiam se beneficiar desses spillovers quanto mais abertas fossem no que se refere à sua capacidade absortiva de conhecimento. No entanto, este fato não foi observado nas empresas brasileiras deste estudo, que se mostraram fechadas às redes externas de colaboração.

Todas as dimensões verificadas acima, tanto as relacionadas às capacidades absortivas quanto as relativas às boas práticas de gestão, repercutem sobre a dinâmica de inovação, e esta sobre a produtividade das firmas, o que por si só contribui para a melhoria da performance.

Ao se analisar de forma conjunta o resultado de campo, possibilita-se um novo entendimento sobre a dinâmica da produtividade das firmas. Tais evidências permitem que se construa um modelo analítico, como pode ser observado na Figura 1. 


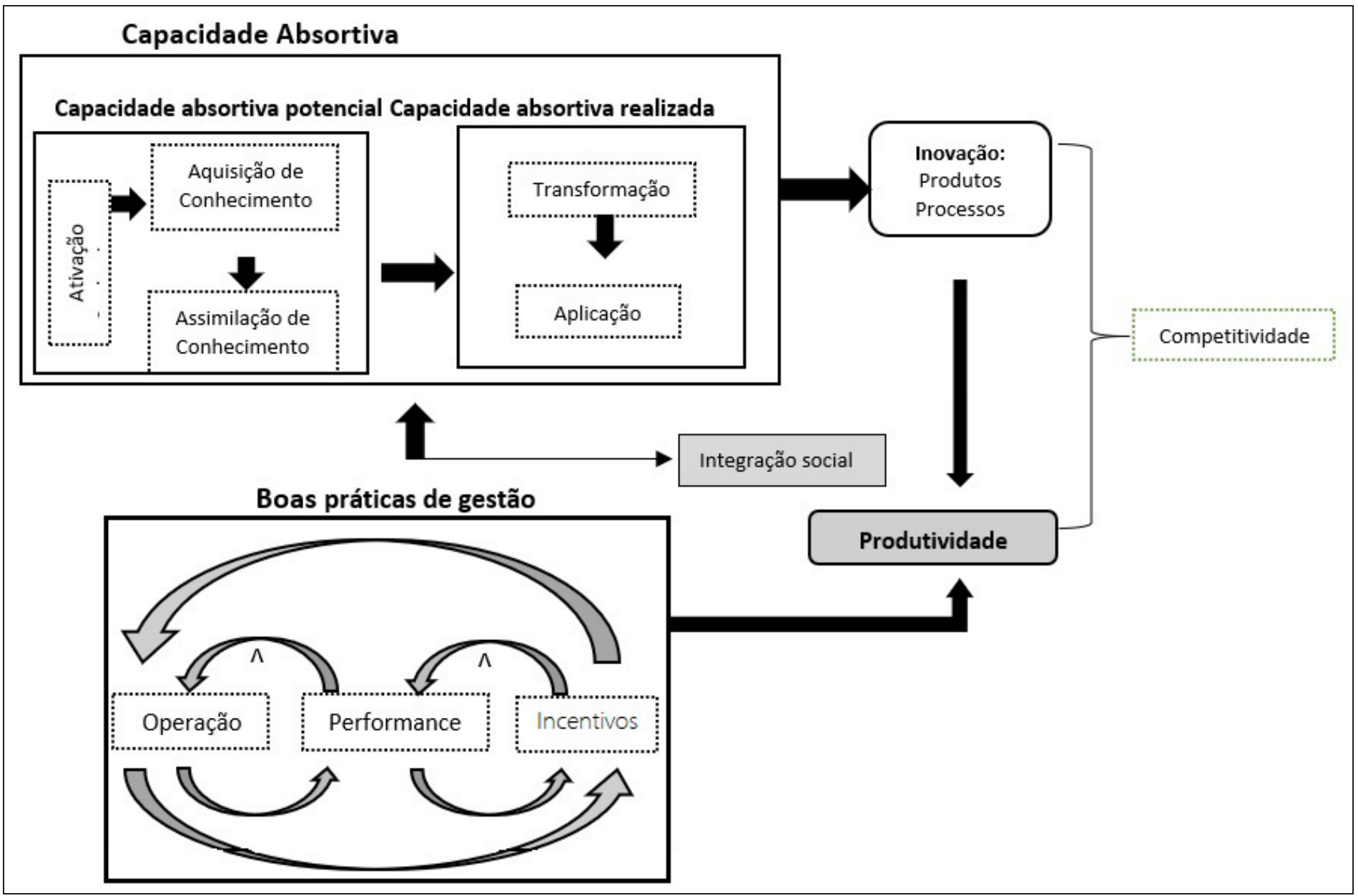

Figura 1. Modelo analítico da relação entre boas práticas de gestão e capacidade absortiva.

Em relação ao modelo da Figura 1, percebe-se que o destino principal do modelo é a produtividade, consubstanciando o esforço que se pretendeu com este trabalho, que é o de demonstrar os efeitos de uma firma possuir boas práticas de gestão aliadas à sua capacidade absortiva e o modo pelo qual estas influenciam a primeira, além de como essas variáveis interagem entre si.

Ao se olhar para o modelo, verifica-se que as variáveis contempladas dentro da caixa referente às boas práticas de gestão (Operação, Performance e Incentivos) interagem entre si, retroalimentando-se e formando um processo de gestão que influencia inclusive as rotinas de capacidade absortiva, sendo essa integração reforçada pelos mecanismos de integração social e impulsionada desde o começo por mecanismos de ativação (crises ou detecção de oportunidades). Essas rotinas, apesar de manterem suas especificidades, beneficiam-se em termos de resultados quando há na empresa uma cultura direcionada à boa gestão.

\section{CONCLUSÕES}

Esta pesquisa pretendeu investigar de que modo ocorre a interação entre as variáveis boas práticas de gestão e capacidade absortiva e, consequentemente, o impacto desta interação sobre a produtividade das firmas. Além disso, foram comparadas as diferenças de padrões nessas áreas em empresas nacionais e transnacionais com presença no território brasileiro.

Constata-se que não há como negligenciar a importância da existência das boas práticas de gestão no contexto de inovação e da competitividade das firmas (Agarwal et al., 2014; Bloom \& Van Reenen, 2010; Bloom et al., 2019; Feldmann et al., 2019). É evidenciado o papel dessa variável como elemento aglutinador e direcionador das atividades na busca de conhecimento externo - capacidade absortiva - com vistas a melhorar a produtividade e, consequentemente, a performance das firmas. 
Assim, a tarefa de gestão assume um papel importante como influenciadora dos processos de capacidade absortiva (Guimarães, Thielman, Guimarães, \& Cornick, 2016), já que, por meio da primeira, a empresa adota padrões de atuação que de forma indireta contribuem para o aumento do conhecimento advindo de fontes externas à organização, o que repercute diretamente na sua performance, garantindo-lhe maior inserção competitiva. Esses efeitos são potencializados quando a empresa investe em áreas que aumentam a integração social (Morano et al., 2016; Vega-Jurado et al., 2008; Zahra \& George, 2002), formando um ambiente onde a criatividade e o conhecimento fluem mais livremente.

Por outro lado, não haveria como analisar de forma isolada esses dois elementos - boas práticas de gestão e capacidades absortivas, em função dos seus efeitos sobre a produtividade das firmas, uma vez que eles agem de forma complementar sobre esta última, como pôde ser verificado nas constatações de campo, resultando no modelo analítico, conforme a Figura 1.

O resultado de um bom processo de capacidade absortiva pode ser materializado na forma de inovações, e estas, em grande medida, contribuem para o aumento da produtividade. Por outro lado, o aumento da produtividade também é proporcionado pela existência de um bom processo de gestão na empresa, e este, de forma adjacente, reforça ainda mais a capacidade absortiva. Não obstante, o aumento da produtividade, tanto em função das inovações quanto em função de um processo de gestão eficiente, insere a empresa em uma melhor condição de competir nos seus mercados de atuação.

Dessa forma, pôde ser evidenciada neste trabalho a relação entre as melhores práticas de gestão e a capacidade absortiva, assim como o grau com que essas variáveis combinadas influenciam o nível de produtividade das firmas. Além disso, puderam ser verificadas diferenças significativas nas práticas adotadas entre as empresas brasileiras e as subsidiárias estrangeiras nesses elementos de análise, corroborando

\section{REFERENNCIAS}

Abiplast, Associação Brasileira da Indústria do Plástico. (2015). Perfil da indústria de plásticos no Brasil. Retrieved from http://file.abiplast.org.br/download/2016/ perfil_2015_ok.pdf

Agarwal, R., Brown, P. J., Green, R., Randhawa, K., \& Tan, H. (2014). Management practices of Australian manufacturing firms: Why are some firms more innovative? International Journal of Production Research, 52(21), 6496-6517. https://doi.org/10.1080 /00207543.2014.949362

Angrosino, M. (2009). Etnografia e observação participante. Porto Alegre: Artmed. os estudos de Bloom e Van Reenen (2010). Enquanto as empresas transnacionais são mais pragmáticas e direcionadas a resultados, as empresas brasileiras são mais indolentes e carecem de mecanismos mais efetivos de gestão.

Isto posto, a própria tarefa de absorção do conhecimento externo e sua internalização em termos de rotinas e procedimentos ficam prejudicados pela baixa efetividade da tarefa de gestão. Além disso, as empresas nacionais são fechadas, não atuando em redes de colaboração com universidades, institutos de pesquisa, clientes e fornecedores, o que poderia impulsionar suas rotinas de gerenciamento da inovação.

Não obstante, frisa-se que as considerações resultantes aqui são limitadas pelo próprio método utilizado, uma abordagem qualitativa, não podendo, portanto, ser generalizadas. Além disso, na triangulação em relação aos efeitos combinados dos elementos aqui estudados (boas práticas de gestão e capacidade absortiva) e seus impactos sobre a produtividade, não se levou em conta a participação de variáveis exógenas, como, por exemplo, o ambiente macroeconômico. Assim, não se negligencia neste estudo que variáveis dessa natureza podem também influir na produtividade das firmas. Ademais, a própria política das organizações, tendo em vista a estrutura do capital e o tamanho das operações, dentre outros fatores, impõe limites para que se possa chegar a conclusões mais sólidas.

Já em relação ao método utilizado para calcular a produtividade em função da indisponibilidade de alguns dados por parte das empresas, apesar de ter sido utilizado um método chancelado pela OCDE, o da produtividade do trabalho, seria mais adequado se o indicador tivesse sido o da produtividade total dos fatores. Ademais, sugere-se que sejam desenvolvidos estudos quantitativos a partir do modelo analítico, como, por exemplo, o das equações estruturais, a fim de medir estatisticamente o poder de relação entre as variáveis aqui apresentadas e confirmar o modelo teórico, bem como a inversão da relação - verificar se a capacidade absortiva influencia as boas práticas de gestão.

Armstrong, C. E., \& Lengnick-Hall, C. A. (2013). The Pandora's box of social integration mechanisms: Can they make it more difficult to realize absorptive capacity? Journal of Strategy and Management, 6(1), 4-26. https://doi. org/10.1108/17554251311296530

Bertrand, O., \& Mol, M. J. (2013). The antecedents and innovation effects of domestic and offshore R \& D outsourcing: The contingent impact of cognitive distance and absorptive capacity. Strategic Management Journal, 34(6), 751-760. https://doi.org/10.1002/smj.2034 
Bloom, N., Brynjolfsson, E., Foster, L., Jarmin, R., Patnaik, M., Saporta-Eksten, I., \& Van Reenen, J. (2019). What drives differences in management practices? American Economic Review, 109(5), 1648-1683. https://doi. org/10.1257/aer.20170491

Bloom, N., \& Van Reenen, J. (2006). Measuring and explaining management practices across firms and countries [CEP Discussion Paper No. 716]. Centre for Economic Performance, London, United Kingdom.

Bloom, N., Van Reenen, J. (2007). Measuring and explaining management practices across firms and countries. The Quarterly Journal of Economics, 122(4), 1351-1408. https://doi.org/10.1162/qjec.2007.122.4.1351

Bloom, N., \& Van Reenen, J. (2010). Why do management practices differ across firms and countries? Journal of Economic Perspectives, 24(1), 203-224. https://doi. org/10.1257/jep.24.1.203

Brettel, M., Greve, G. I., \& Flatten, T. C. (2011). Giving up linearity: Absorptive capacity and performance. Journal of Managerial Issues, 23(2), 164-189. Retrieved from https://www.jstor.org/stable/23209224

Carayannis, E., \& Grigoroudius, E. (2014). Linking innovation, productivity, and competitiveness: Implications for policy and practice. The Journal of Technology Transfer, 39(2), 199-218. Retrieved from https:// ideas.repec.org/a/kap/jtecht/v39y2014i2p199-218. html

Cardozo, C. T., Kronmeyer Filho, O. R., \& Vaccaro, G. L. R. (2019). Keep innovating: Absorptive capacity and the performance of Brazilian information technology companies. Revista de Administração Contemporânea, 23(4), 499-519. https://doi.org/10.1590/19827849rac2019180221

Chandler, A. D., \& Hikino, T. (1994). Scale and scope: The dynamics of industrial capitalism. Cambridge, MA: Belknap Press of Harvard University Press.

Choi, S. (2014). Developing relationship-specific memory and absorptive capacity in interorganizational relationships. Information Technology and Management, 15(4), 223-238. https://doi. org/10.1007/s10799-014-0181-5

Cohen, W. M., \& Levinthal, D. A. (1990). Absorptive capacity: A new perspective on learning and innovation. Administrative Science Quarterly, 35(1), 128-152. https://doi.org/10.2307/2393553

Cuervo-Cazurra, A. (2017). Barriers to absorptive capacity in emerging markets firms. Journal of World Business, 52(6), 727-742. https://doi.org/10.1016/j. jwb.2017.06.004

Eisenhardt, K. M. (1989). Building theories from case study research. Academy of Management Review, 14(4), 532550. https://doi.org/10.2307/258557

Feldmann, P. R., Jacomossi, R., Barrichello, A., \& Morano, R. S. (2019). The relationship between innovation and global competitiveness: The mediating role of management practices evaluated by structural equation modeling. Revista Brasileira de Gestão de Negócios, 21(2), 195212. https://doi.org/10.7819/rbgn.v21i2.3970
Feldmann, P. R. (2009). O atraso tecnológico da américa latina como decorrência de aspectos geográficos e de fatores microeconômicos interligados. Economia e Sociedade, 18(1), 119-139. https://doi.org/10.1590/S010406182009000100004

Freeman, C. (1987). Technology policy and economic performance: Lesson from Japan. New York: Frances Printer Publishers.

Godoy, A. S. (2006). Estudo de caso qualitativo. In C. K. Godoi, R. B. de Mello, \& A. B. Silva (Eds.), Pesquisa qualitativa em estudos organizacionais: Paradigmas, estratégias e métodos (pp. 115-146). São Paulo: Saraiva.

Gordon, R. J. (2016). The rise and fall of American growth: The U.S. standard of living since the civil war. New Jersey: Princeton.

Griliches, Z. (1979). Issues in assessing the contribution of R\&D to productivity growth. Bell Journal of Economics, 10(1), 92-116. https://doi.org/10.2307/3003321

Guimarães, T., Thielman, B., Guimarães, V. C., \& Cornick, M. (2016). Absorptive capacity as moderator for company innovation success. International Journal of the Academic Business World, 10(2), 1-18.

Jacomossi, R. R., \& Demajorovic, J. (2017). Fatores determinantes da aprendizagem organizacional para a inovação ambiental: Um estudo multicaso. Revista de Administração Contemporânea, 21(5), 685-709. https://doi.org/10.1590/1982-7849rac2017160281

Kerzner, H. (2018). Project management best practices: Achieving global excellence. New York: Wiley.

Kim, M. (2016). Erratum to: Productivity spillovers from FDI and the role of domestic firm's absorptive capacity in South Korean manufacturing industries. Empirical Economics, 50(4), 1647. https://doi.org/10.1007/ s00181-015-0973-4

Kostopoulos, K., Papalexandris, A., Papachroni, M., \& Ioannou, G. (2011). Absorptive capacity, innovation, and financial performance. Journal of Business Research, 64(12), 1335-1343. https://doi.org/10.1016/j. jbusres.2010.12.005

Landes, D. S. (1969). The unbound prometheus: Technological change and industrial development in western Europe from 1750 to the present. London: Cambridge University Press.

Ledereman, D., Messina, J., Pienknagura, S., \& Rigolini, J. (2014). Latin american entrepreneurs: Many firms but little innovation. Washington, DC: The World Bank.

Mairesse, J., P., \& Robin, S. (2009). Innovation and productivity: A firm-level analysis for French manufacturing and services using CIS3 and CIS4 data (1998-2000 and 2002-2004). Paris: CREST-ENSAE.

Maloney, W. F., \& Sarrias, M. (2014). Convergence to the managerial frontier [Policy research working paper No. 6822]. The World Bank, Washington, DC. Retrieved from: http://documents.worldbank.org/curated/ en/925191468325272296/Convergence-to-themanagerial-frontier

Medda, G., \& Piga, C. A. (2014). Technological spillovers and productivity in Italian manufacturing firms. Journal of Productivity Analysis, 41, 419-434. https://doi. org/10.1007/s11123-013-0351-1 
Morano, R. S., Barrichello, A., \& Jacomossi, R. R. (2016). A ação da identidade social sobre o comportamento discricionário de funcionários: Uma perspectiva brasileira. Revista Ciências Administrativas, 22(1), 283-305. Retrieved from https://periodicos.unifor.br/ rca/article/download/4056/pdf

Morano, R. S, Moraes, E. A. de, \& Jacomossi, R. R. (2018). Can small groups avoid the tragedy of the commoms? AI \& Society, 33, 71-80. https://doi.org/10.1007/s00146017-0720-9

Mozzato, A. R., \& Grzybovski, D. (2011). Análise de conteúdo como técnica de análise de dados qualitativos no campo da administração: Potencial e desafios. Revista de Administração Contemporânea, 15(4), 731-747. https://doi.org/10.1590/S1415-65552011000400013

Müller-Seitz, G., \& Güttel, W. (2014). Toward a choreography of congregating: A practice-based perspective on organizational absorptive capacity in a semiconductor industry consortium. ManagementLearning, 45(4), 477497. https://doi.org/10.1177\%2F1350507613497323

Mundlack, Y. (1961). Empirical production function free of management bias. American Journal of Agricultural Economics, 43(1), 44-56. https://doi. org/10.2307/1235460

Nelson, R. R., \& Winter, S. G. (1982). An evolutionary theory of economic change. Cambridge: The Belknap Press of Harvard University Press.

Nonaka, I., \& Takeuchi, H. (1995). The knowledge creating firm: How Japanese firms create the dynamics of innovation. New York: Oxford University Press.

Organisation for Economic Co-operation and Development. (2001). Measuring productivity: Measurement of aggregate and industry-level productivity growth. Retrieved from http://www.oecd.org/sdd/ productivity-stats/2352458.pdf

Parisi, M. L., Schiantarelli, F., \& Sembenelli, A. (2006). Productivity, innovation and R\&D: Micro-evidence for Italy. European Economic Review, 50(8), 2037-2061. https://doi.org/10.1016/j.euroecorev.2005.08.002

Pavitt, K. (1984). Sectoral patterns of technical change: Towards a taxonomy and a theory. Research Policy, 13(6), 343373. https://doi.org/10.1016/0048-7333(84)90018-0

Phoocharoon, P. (2015). Enhancing potential and realised absorptive capacity: Macro-micro dynamic integrative design. International Journal of Innovation Management, 19(5), e1550058. https://doi. org/10.1142/S1363919615500589

Ritala, P., \& Hurmelinna-Laukkanen, P. (2013). Incremental and radical innovation in coopetition - The role of absorptive capacity and appropriability. The Journal of Product Innovation Management, 30(1), 154-169. https://doi.org/10.1111/j.1540-5885.2012.00956.x
Schumpeter, J. A. (1982). Teoria do desenvolvimento econômico. São Paulo: Abril.

Tavani, S. N., Sharifi, H., \& Ismail, H. S. (2014). A study of contingency relationships between supplier involvement, absorptive capacity and agile product innovation. International Journal of Operations \& Production Management, 34(1), 65-92. https://doi. org/0.1108/IJOPM-09-2011-0331

Vega-Jurado, J., Gutiérrez-Gracia, A., \& Fernández-de-Lucio, I. (2008). Analyzing the determinants of firm's absorptive capacity: beyond R\&D. R\&D Management, 38(4), 392-405. https://doi.org/10.1111/j.14679310.2008.00525.x

Venkatraman, N., \& Ramanujam, V. (1987). Measurement of business economic performance: An examination of method convergence. Journal of Management, 13(1), 109-122. https://doi.org/10.1177\% 2F014920638701300109

Wakelin, K. (2001). Productivity growth and R\&D expenditure in UK manufacturing firms. Research Policy, 30(7), 10791090. https://doi.org/10.1016/S0048-7333(00)001360

Walsh, J. P., \& Ungson, G. R. (1991). Organizational memory. Academy of Management Review, 16(1), 57-91. https:// doi.org/10.5465/amr.1991.4278992

Wang, C., \& Han, Y. (2011). Linking properties of knowledge with innovation performance: The moderate role of absorptive capacity. Journal of Knowledge Management, 15(5), 802-819. https://doi. org/10.1108/13673271111174339

Wang, L., Zhao, J. Z., \& Zhou, K. Z. (2018). How do incentives motivate absorptive capacity development? The mediating role of employee learning and relational contingencies. Journal of Business Research, 85, 226237. https://doi.org/10.1016/j.jbusres.2018.01.010

Wiengarten, F., Gimenez, C., Fynes, B., \& Ferdows, K. (2015). Exploring the importance of cultural collectivism on the efficacy of lean practices: Taking an organisational and national perspective. International Journal of Operations \& Production Management, 35(3), 370-391. https://doi.org/0.1108/IJOPM-09-2012-0357

Wu, S. J. (2015). The impact of quality culture on quality management practices and performance in Chinese manufacturing firms. International Journal of Quality \& Reliability Management, 32(8), 799-814. https://doi. org/10.1108/IJQRM-12-2013-0199

Zahra, S. A., \& George, G. (2002). Absorptive capacity: A review, reconceptualization, and extension. Academy of Management Review, 27(2), 185-203. https://doi. org/10.5465/amr.2002.6587995 


\section{Autoria}

\section{Rafael Ricardo Jacomossi*}

Av. Humberto de Alencar Castelo Branco, no 3972-B, Assunção, 09850-901, São Bernardo do Campo, SP, Brasil.

E-mail: rjacomossi@fei.edu.br

(1) https://orcid.org/0000-0001-5584-142X

\section{Paulo Roberto Feldmann}

Av. Prof. Luciano Gualberto, nº 908, Butantã, 05508-010, São Paulo, SP, Brasil.

E-mail: feldmann@usp.br

(1) https://orcid.org/0000-0001-5662-8735

* Autor Correspondente

\section{Contribuições dos Autores}

10 autor: contribuiu igualmente para a conceituação; curadoria de dados; análise formal; investigação; metodologia; administração de projeto; recursos; software; supervisão; validação; visualização; escrita - rascunho original; escrita - revisão e edição.

$2^{\circ}$ autor: contribuiu igualmente para a conceituação; curadoria de dados; análise formal; aquisição de financiamento; investigação; metodologia; administração de projeto; recursos; software; supervisão; validação; visualização; escrita - rascunho original; escrita - revisão e edição.

\section{Financiamento}

Os autores agradecem ao Conselho Nacional de Desenvolvimento Científico e Tecnológico - (CNPq - Projeto $\left.\mathrm{n}^{\mathrm{o}} 152128 / 2016-6\right)$ pelo suporte a este trabalho.

\section{Conflito de Interesses}

Os autores informaram que não há conflito de interesses.

\section{Direitos Autorais}

A RAC detém os direitos autorais deste conteúdo.

\section{Verificação de Plágio}

A RAC mantém a prática de submeter todos os documentos aprovados para publicação à verificação de plágio, mediante o emprego de ferramentas específicas, e.g.: iThenticate.

\section{Método de Revisão por Pares}

Este conteúdo foi avaliado utilizando o processo de revisão por pares duplo-cego (double-blind peer-review). A divulgação das informações dos pareceristas constantes na primeira página é feita somente após a conclusão do processo avaliativo, e com o consentimento voluntário dos respectivos pareceristas. 